\title{
Catalytic Ozonation of Sulfonamide, Fluoroquinolone, and Tetracycline Antibiotics Using Nano-Magnesium Hydroxide from Natural Bischofite
}

\author{
Qi Sun • Jian Lu $(\mathbb{D} \cdot$ Jun Wu • Guangcan Zhu
}

Received: 20 July 2018 / Accepted: 4 February 2019 /Published online: 12 February 2019

(C) Springer Nature Switzerland AG 2019

\begin{abstract}
Huge amounts of natural bischofite $\left(\mathrm{MgCl}_{2} \cdot 6 \mathrm{H}_{2} \mathrm{O}\right)$ resulting from the mining process of salt lakes often cannot be utilized effectively and are discarded; techniques for reutilization of the discarded bischofite as magnesium resources are limited. The nano-magnesium hydroxide (nano- $\mathrm{Mg}(\mathrm{OH})_{2}$ ) synthesized from natural bischofite was firstly used as catalyst for ozonation of antibiotics including sulfathiazole (ST), ofloxacin (OFL), and tetracycline (TC). Rapid ozonation of ST, OFL, and TC was achieved using nano$\mathrm{Mg}(\mathrm{OH})_{2}$ as catalyst. The removal rate constant of OFL in the catalytic ozonation treatment $\left(\mathrm{k}_{\mathrm{OFL}}=\right.$ $0.512 \mathrm{~min}^{-1}$ ) was nearly 2.1 times higher than the single ozonation $\left(\mathrm{k}_{\mathrm{OFL}}=0.249 \mathrm{~min}^{-1}\right)$. The removal rate constant of ST and TC increased by $23.5 \%$ and $32.8 \%$ from $0.298 \mathrm{~min}^{-1}$ and $0.384 \mathrm{~min}^{-1}$ to $0.368 \mathrm{~min}^{-1}$ and
\end{abstract}

\footnotetext{
Q. Sun · J. Lu ( $\bowtie)$

CAS Key Laboratory of Coastal Environmental Processes and Ecological Remediation, Yantai Institute of Coastal Zone Research (YIC), Chinese Academy of Sciences (CAS), Beijing, China e-mail: jlu@yic.ac.cn

Q. Sun · J. Lu

Shandong Key Laboratory of Coastal Environmental Processes, YICCAS, Yantai, Shandong 264003, People's Republic of China

Q. Sun · G. Zhu

School of Energy and Environment, Southeast University,

Nanjing, Jiangsu 210096, People's Republic of China

J. Wu

Qinghai Institute of Salt Lakes, Chinese Academy of Sciences, Xining, Qinghai 810008, People's Republic of China
}

$0.510 \mathrm{~min}^{-1}$, respectively, when the catalyst was added into the reaction system. The removal rate constant of ST sharply increased from 0.259 to $0.604 \mathrm{~min}^{-1}$ when the reaction temperature increased from 15 to $35{ }^{\circ} \mathrm{C}$ while those of OFL and TC changes slightly. The removal efficiency sharply decreased when the initial concentration of ST, OFL, and TC increased from 10 to $500 \mathrm{mg} \mathrm{L}^{-1}$. Both anions and cations could inhibit the removal of ST, OFL, and TC at relatively higher concentrations. The prepared nano- $\mathrm{Mg}(\mathrm{OH})_{2}$ catalyst could maintain its catalytic activity in the repeated use process. High removal efficiency of typical antibiotics and heavy metals free indicated that nano- $\mathrm{Mg}(\mathrm{OH})_{2}$ from natural bischofite is a promising ozonation catalyst in terms of antibiotics removal.

Keywords Nano-magnesium hydroxide Catalytic ozonation $\cdot$ Bischofite $\cdot$ Antibiotics

\section{Introduction}

Rapid industrialization has led to the introduction of generated hazardous compounds into water bodies and the improper management of contaminated water causes water crises around the world. In addition, numerous pharmaceutical compounds from agricultural runoff, hospitals, and drug-manufacturing facilities have made significant contributions to water pollution (Changotra et al. 2018). The widespread desire and use of antibiotics among these pharmaceutical compounds has received increasing attention. A large amount of antibiotics have 
been widely used as antimicrobials and growth promoters for both human beings and animals (Kümmerer 2009). These contaminants and/or their intermediates are discharged into the environment after their use through a variety of routes. As a result, these antibiotics have been frequently detected in various aquatic environments, especially pharmaceutical wastewater (Peng et al. 2006; Yan et al. 2013). Although their concentrations in the aquatic environment are usually within the range of $\mathrm{ng} \mathrm{L}^{-1}$ to $\mathrm{mg} \mathrm{L}^{-1}$ (Brown et al. 2006; Managaki et al. 2007), continuous accumulation of these pollutants may cause long-term harm to human, plants, and animals (Trovó et al. 2009; Carvalho and Santos 2016). In addition, these compounds have antibacterial properties (Trovó et al. 2009). Thus, even at very low concentrations, the presence of antibiotics in water can lead to the increase of the bacterial resistance against antibiotics (Carvalho and Santos 2016; Yin et al. 2017). Sulfathiazole (ST, representative sulfonamides), ofloxacin (OFL, typical fluoroquinolones), and tetracycline (TC, typical tetracyclines) have been widely used for treating infectious diseases of both human beings and animals. These antibiotics are polar and nonvolatile compounds (Peng et al. 2006), possessing high anti-degradation ability and being hydrophilic enough to readily enter into the aquatic environment (Kümmerer 2001; Miao et al. 2004). The conventional treatment processes are not very effective for the removal of antibiotics existing in pharmaceutical wastewater (Kim et al. 2007; Vieno et al. 2007).

The advanced oxidation processes (AOPs) such as the UV photocatalytic oxidation, Fenton and Fenton-like process, gamma irradiation, and ozonation have been used to remove antibiotics (Trovó et al. 2009; Hou et al. 2013a, b; Yuan et al. 2013; Changotra et al. 2018). As an among various AOPs, the catalytic ozonation is a novel advanced oxidation process widely used for efficiently eliminating refractory organic compounds with the short reaction time and high removal efficiency (Amutha et al. 2014; Bai et al. 2016). Various nano-scale materials including composite iron oxides (Bai et al. 2016), carbon materials (Gonçalves et al. 2012; Tian et al. 2013), and heteroatom-doped grapheme (Yin et al. 2017) have been used for catalyzing ozonation of various pollutants. However, rare reports are available on the catalytic ozonation of antibiotics (e.g., sulfathiazole, ofloxacin, and tetracycline) using nano$\mathrm{Mg}(\mathrm{OH})_{2}$ as catalyst.

As an environment-friendly material, $\mathrm{Mg}(\mathrm{OH})_{2}$ has attracted wide attention (Dong et al. 2007; He et al. 2008) and has shown high catalytic performance for the ozonation of phenol, nitrobenzene, and aniline (Dong et al. 2007; He et al. 2008). Huge amounts of natural bischofite $\left(\mathrm{MgCl}_{2} \cdot 6 \mathrm{H}_{2} \mathrm{O}\right)$ resulting from the mining process of salt lakes often cannot be utilized effectively and are discarded, which led to the waste of valuable magnesium resources. Techniques for reutilization of the discarded bischofite as magnesium resources are limited. This study firstly investigated the catalytic ozonation of widely used antibiotics including ST, OFL, and TC using nano- $\mathrm{Mg}(\mathrm{OH})_{2}$ synthesized from natural bischofite. The effects of various parameters including radical scavenger, reaction temperature, antibiotic concentrations, anions, and cations on the removal of these antibiotics were evaluated. The aim of this study was to obtain initial information on the catalytic ozonation of typical widely used antibiotics using nano- $\mathrm{Mg}(\mathrm{OH})_{2}$ made from natural bischofite as catalyst.

\section{Materials and Methods}

\subsection{Materials and Reagents}

The selected antibiotics including sulfathiazole (ST, purity $\geq 99.0 \%$ ), ofloxacin (OFL, purity $\geq 98.5 \%$ ), and tetracycline (TC, purity $\geq 98.0 \%$ ) were obtained from TCI (Shanghai, China), Macklin (Shanghai, China), and Aladdin (Shanghai, China), respectively. Natural bischofite $\left(\mathrm{MgCl}_{2} \cdot 6 \mathrm{H}_{2} \mathrm{O}\right)$ was obtained from Qarhan Salt Lake, China. Sodium chloride, sodium bicarbonate, anhydrous sodium sulfate, calcium chloride, potassium iodide, polyethylene glycol (PEG 400), and ammonium hydroxide were purchased from Sinopharm Chemical Reagent Co. Ltd. (Shanghai, China). Acetonitrile and sodium hydrogen phosphate used for high performance liquid chromatography (HPLC) were of HPLC grade (Mreda, USA) and analytical grade, respectively. Sodium thiosulfate and tert-butanol (TBA) with analytical purity grade were used as quenching agent and radical scavenger, respectively.

\subsection{Preparation of Nano- $\mathrm{Mg}(\mathrm{OH})_{2}$ Catalyst}

Nano- $\mathrm{Mg}(\mathrm{OH})_{2}$ was prepared according to published procedures (Wang et al. 2007) with modifications. Natural bischofite was dissolved in pure water to make the magnesium chloride solution $\left(0.5 \mathrm{~mol} \mathrm{~L}^{-1}\right)$. One hundred milliliters of the magnesium chloride solution and 


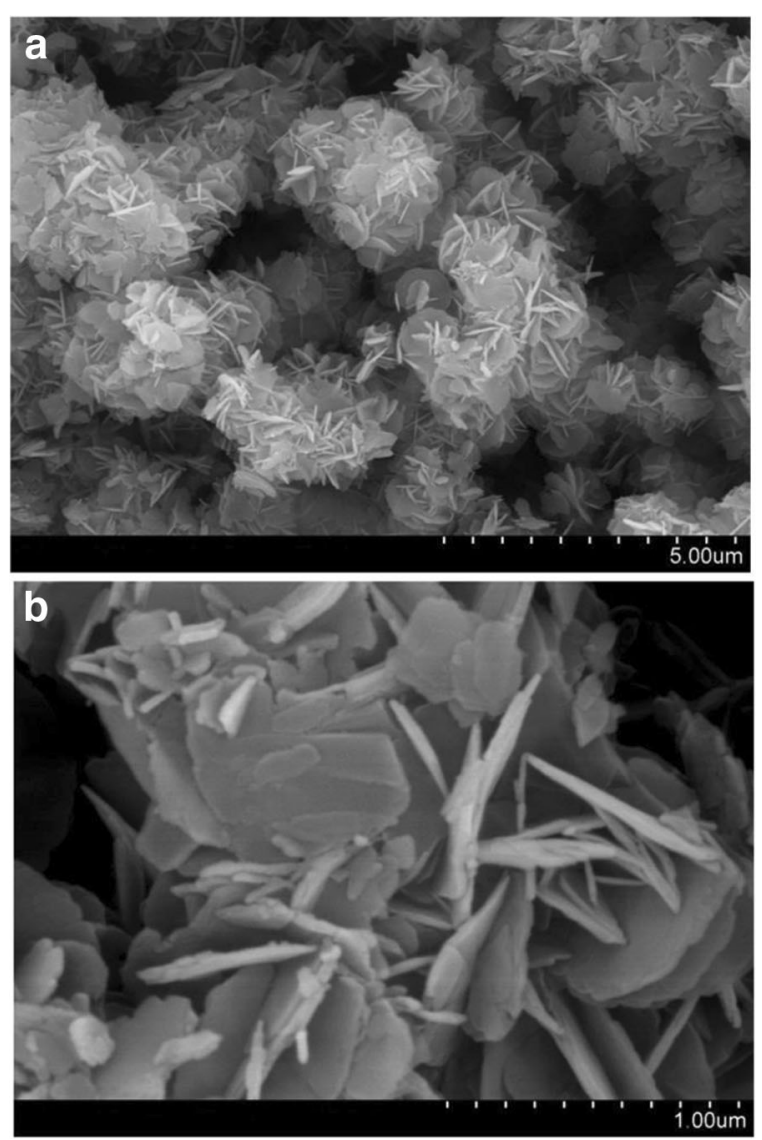

Fig. 1 Scanning electron microscopy (SEM) images of the synthesized nano- $\mathrm{Mg}(\mathrm{OH})_{2}$ at low magnification (a) and high magnification (b) views
$10 \mathrm{~mL}$ of the surfactant PEG400 were mixed, and then placed in the $50{ }^{\circ} \mathrm{C}$ thermostatic water baths. Eight milliliters of ammonium hydroxide was dropwisely added to the above solution during the constant magnetic stirring (1200 $\mathrm{r} \mathrm{min}^{-1}$ ). White suspension was formed when ammonium hydroxide drops were added to the above solution. After 1.5 -h stirring at $50{ }^{\circ} \mathrm{C}$, the obtained suspension was exposed to air for aging at room temperature for $1.5 \mathrm{~h}$. After centrifugal separation, white precipitates were carefully washed for several times by ultrapure water and ethanol in order to remove the ions remaining on the final products. The resultant material was dried in the air for $12 \mathrm{~h}$ at the temperature of $60{ }^{\circ} \mathrm{C}$.

\subsection{Catalytic Ozonation of Antibiotics Using the Nano- $\mathrm{Mg}(\mathrm{OH})_{2}$}

For catalytic ozonation experiments, required concentrations of nano- $\mathrm{Mg}(\mathrm{OH})_{2}$ and $100 \mathrm{~mL}$ antibiotic solution were added into the flask. Then, the applied gas ozone concentration was controlled at $0.5 \mathrm{~g} \mathrm{~h}^{-1}$. During the run, $1 \mathrm{~mL}$ sample was rapidly taken out from the flask at a predetermined time interval and quenched quickly by adding $0.025 \mathrm{~mol} \mathrm{~L}^{-1}$ sodium thiosulfate solution to remove residual ozone. Then, each sample was centrifuged at 12,000 rpm for $6 \mathrm{~min}$ and the supernatant was used to analyze the target parameters. For comparative purposes and discarding the adsorption
Fig. 2 X-ray diffraction (XRD) patterns of the synthesized nano$\mathrm{Mg}(\mathrm{OH})_{2}$

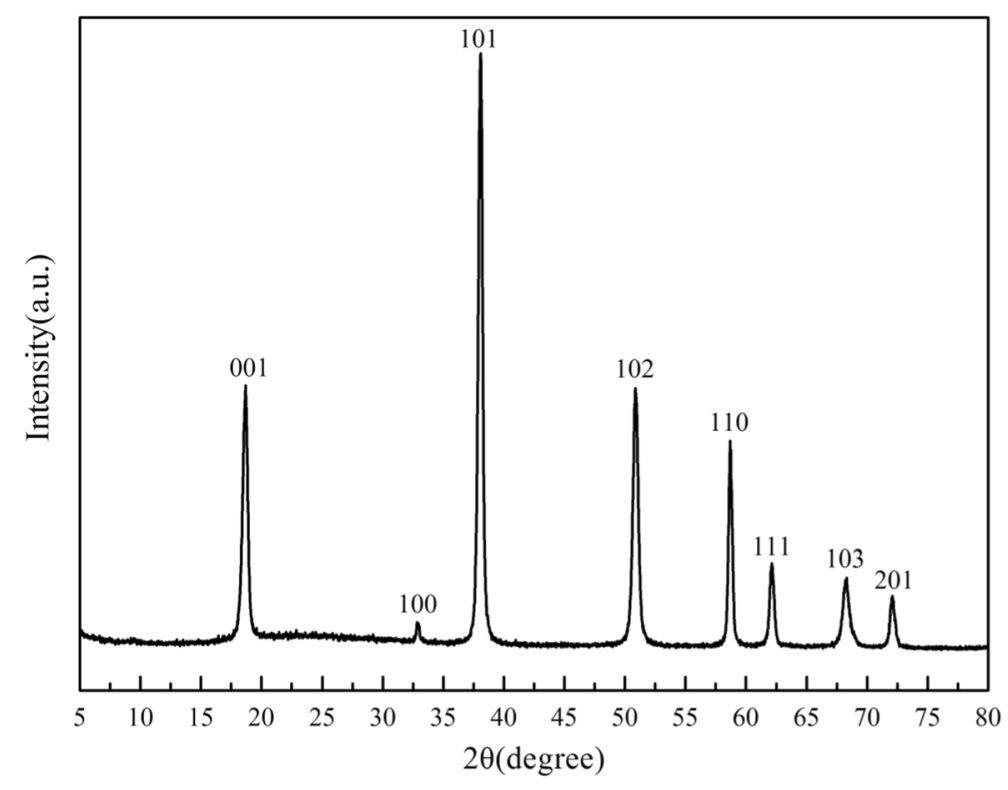


effect of nano- $\mathrm{Mg}(\mathrm{OH})_{2}$ during the experiments, single ozonation experiments and a control trial of oxygen purging with the reaction solution containing the catalyst were conducted under the same conditions. Besides
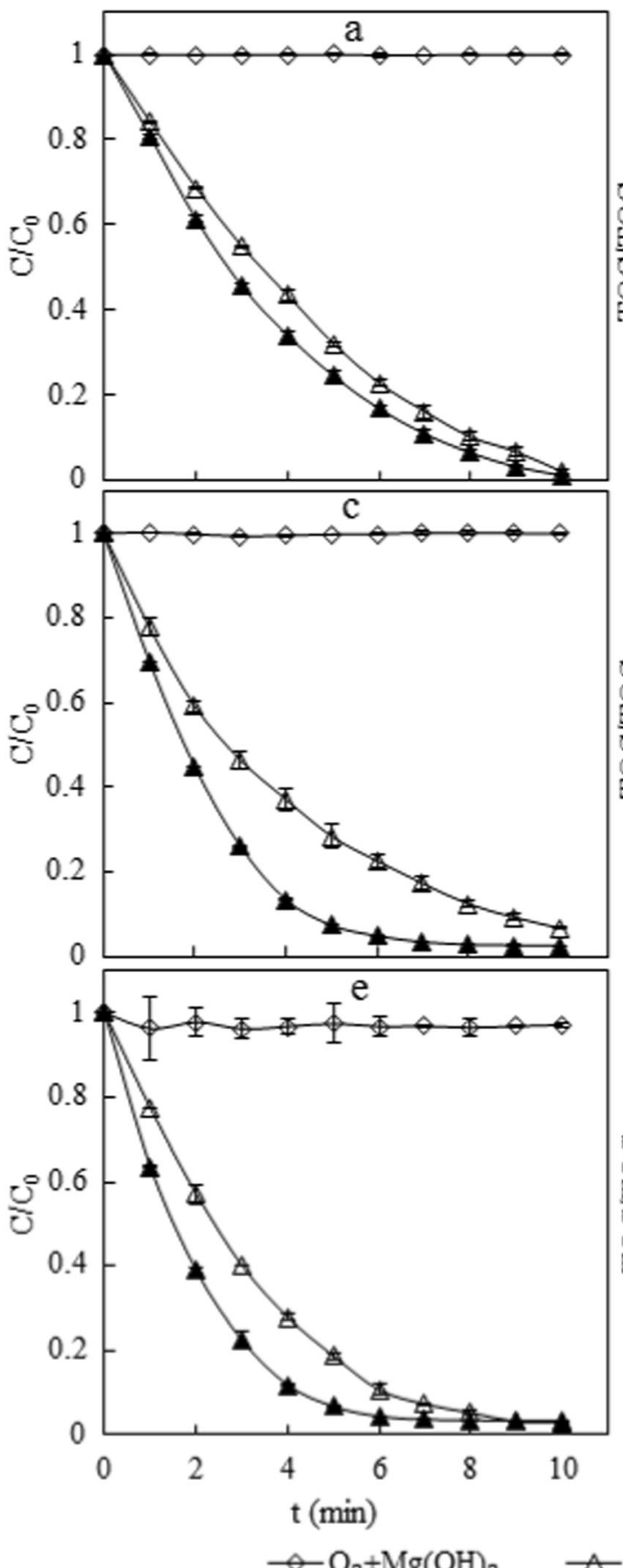

Fig. 3 Degradation and mineralization of sulfathiazole (a, b), ofloxacin $(\mathbf{c}, \mathbf{d})$, and tetracycline $(\mathbf{e}, \mathbf{f})$ in different oxidation treatments. Reaction conditions: antibiotics concentration the influence of several factors on the removal of target antibiotics, the experiments were carried out at initial antibiotics concentration of $50 \mathrm{mg} \mathrm{L}^{-1}$, ozone flow rate of $0.1 \mathrm{~L} \mathrm{~min}^{-1}$, ozone gas concentration of $0.5 \mathrm{~g} \mathrm{~h}^{-1}$, and
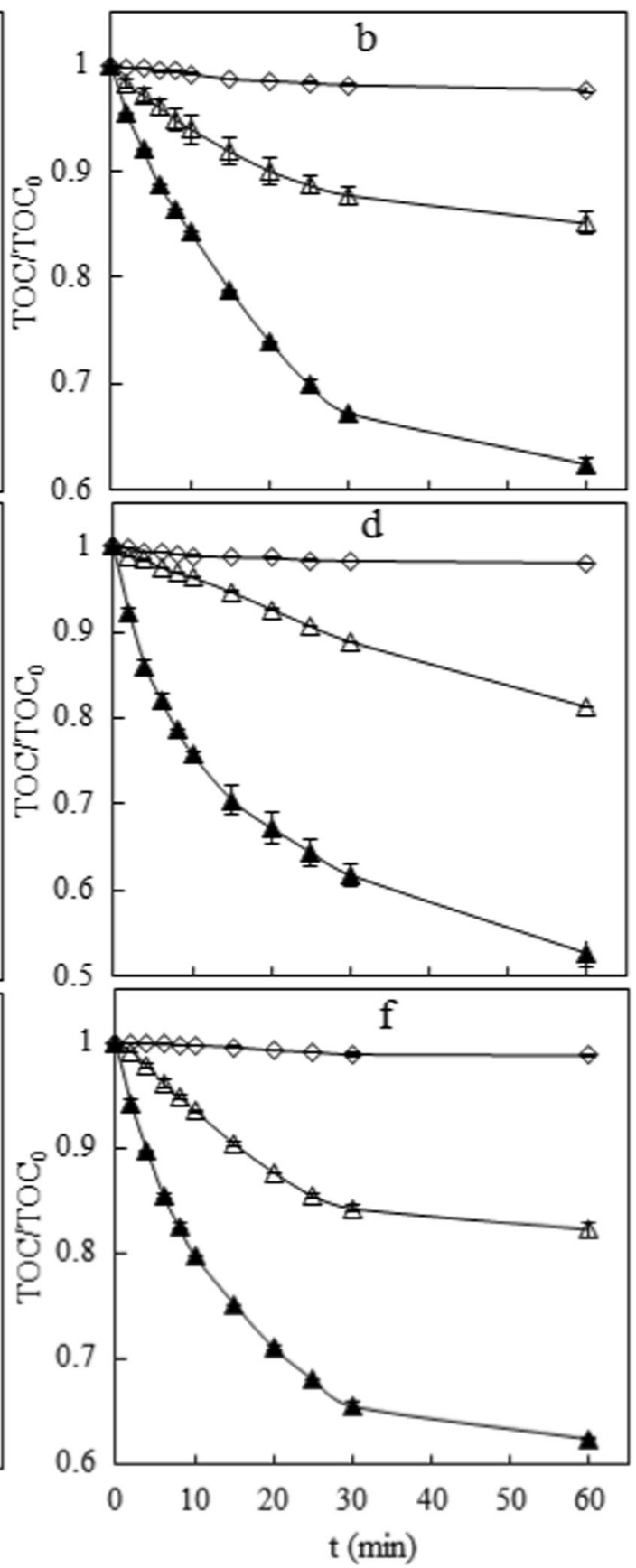

\section{$\mathrm{O}_{3}-\mathrm{O}_{3}+\mathrm{Mg}(\mathrm{OH})_{2}$}

$50 \mathrm{mg} \mathrm{L}^{-1}$, catalyst dosage $0.15 \mathrm{~g} \mathrm{~L}^{-1}$, ozone concentration $0.5 \mathrm{~g} \mathrm{~h}^{-1}$, ozone flow rate $0.1 \mathrm{~L} \mathrm{~min}^{-1}$ 
catalyst dosage of $0.15 \mathrm{~g} \mathrm{~L}^{-1}$. Ozone was produced in pure oxygen by an ozonator (Wohuan Co., Ltd) and was bubbled continuously into the reaction solution through a glass diffuser with a required gas flow rate of $0.1 \mathrm{~L} \mathrm{~min}^{-1}$ during the experiment process. The effluent ozone from the reactor was further treated with $20 \%$ potassium iodide solution. The reaction solution was thoroughly mixed by a magnetic stirrer. All the experiments were performed at $25 \pm 2{ }^{\circ} \mathrm{C}$. Each test was performed in triplicate, and the mean value was presented.

The effects of main influential factors including radical scavenger, reaction temperature, initial antibiotics
Fig. 4 Effect of tert-butanol (TBA) on the degradation of sulfathiazole (a), ofloxacin (b), and tetracycline (c). Reaction conditions: antibiotics concentration $50 \mathrm{mg} \mathrm{L}^{-1}$, catalyst dosage $0.15 \mathrm{~g} \mathrm{~L}^{-1}$, ozone concentration $0.5 \mathrm{~g} \mathrm{~h}^{-1}$, ozone flow rate $0.1 \mathrm{~L} \mathrm{~min}^{-1}$, radical scavenger concentration $0.1 \mathrm{~mol} \mathrm{~L}^{-1}$

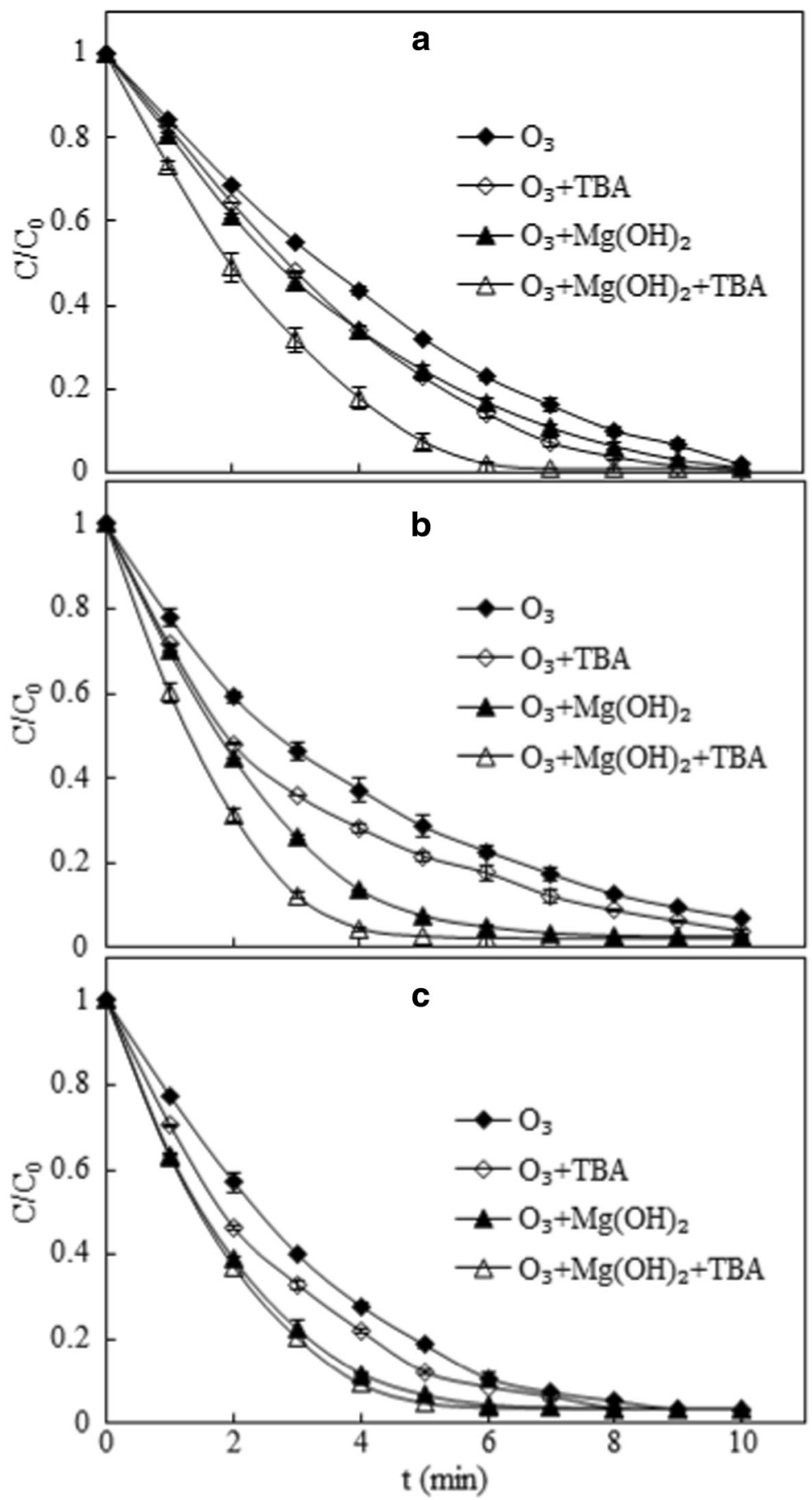


concentration, coexisting anions $\left(\mathrm{Cl}^{-}, \mathrm{HCO}_{3}{ }^{-}, \mathrm{SO}_{4}{ }^{2-}\right)$, and cations $\left(\mathrm{Ca}^{2+}, \mathrm{Mg}^{2+}\right)$ on the catalytic ozonation of antibiotics were evaluated. To investigate the influence of radical scavenger on removal of ST, OFL, and TC, TBA $\left(0.1 \mathrm{~mol} \mathrm{~L}^{-1}\right)$ was added to single ozonation, and catalytic ozonation systems, respectively. The temperature was adjusted by constant temperature bath to $15^{\circ} \mathrm{C}, 25^{\circ} \mathrm{C}$, and $35^{\circ} \mathrm{C}$ to investigate the influence of temperature on the removal of ST, OFL, and TC. The initial concentrations of target antibiotics were set as 10 , $30,50,100,200$, and $500 \mathrm{mg} \mathrm{L}^{-1}$ in the catalytic ozonation process to evaluate the influence of initial
Fig. 5 Effect of temperature on the degradation of sulfathiazole (a), ofloxacin (b), and tetracycline (c). Reaction conditions: antibiotics concentration $50 \mathrm{mg} \mathrm{L}^{-1}$, catalyst dosage $0.15 \mathrm{~g} \mathrm{~L}^{-1}$, ozone concentration $0.5 \mathrm{~g} \mathrm{~h}^{-1}$, ozone flow rate $0.1 \mathrm{~L} \mathrm{~min}^{-1}$

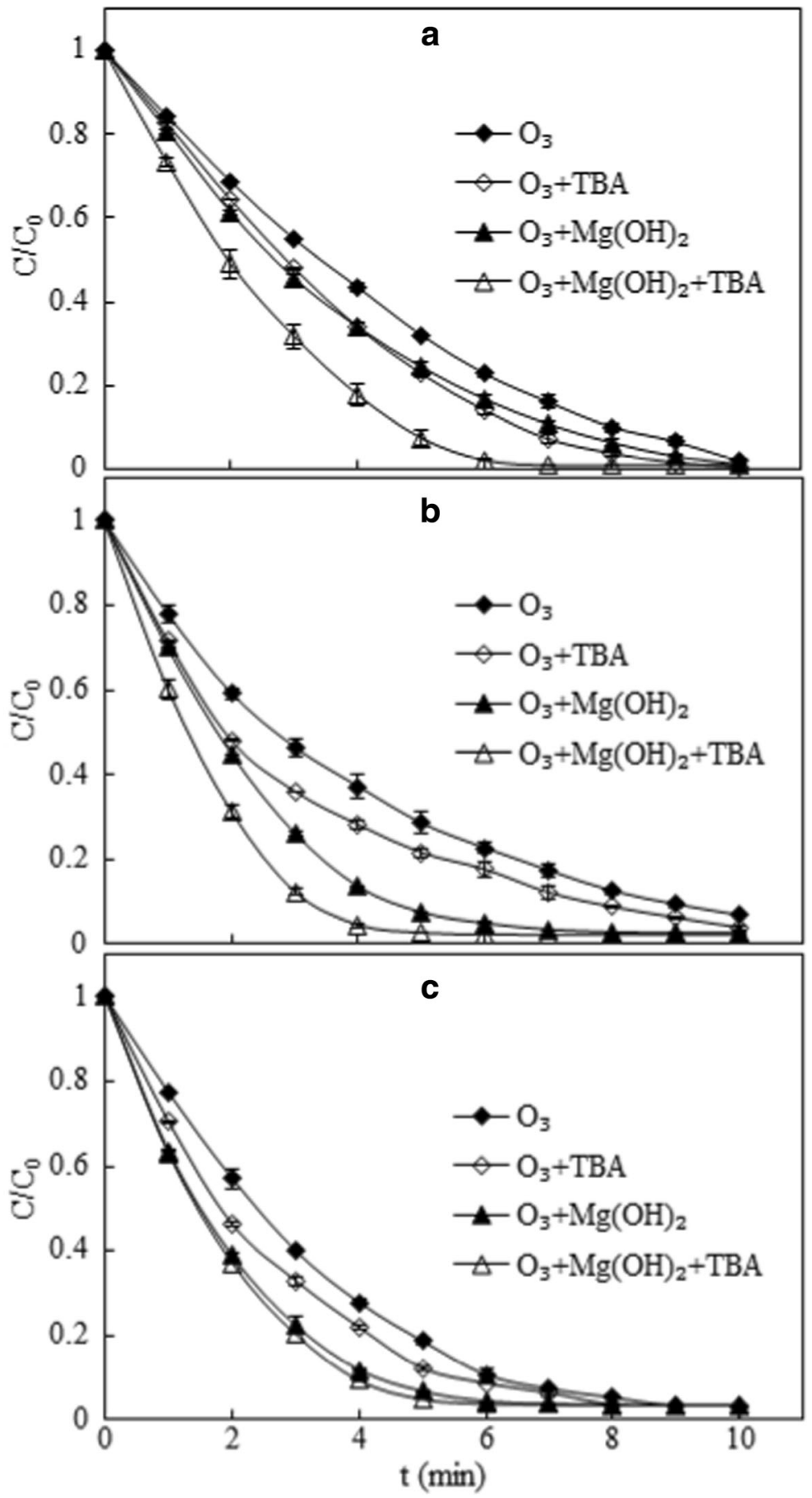


concentration of target compound on the removal efficiency. To evaluate the effect of anions $\left(\mathrm{Cl}^{-}, \mathrm{HCO}_{3}{ }^{-}\right.$, and $\mathrm{SO}_{4}{ }^{2-}$ ) on the removal of ST, OFL, and TC, sodium salt with corresponding concentration $(0,0.005,0.05$,
Fig. 6 Effect of initial concentration of antibiotics on the degradation of sulfathiazole (a), ofloxacin (b), and tetracycline (c). Reaction conditions: catalyst dosage $0.15 \mathrm{~g} \mathrm{~L}^{-1}$, ozone concentration $0.5 \mathrm{~g} \mathrm{~h}^{-1}$, ozone flow rate $0.1 \mathrm{~L} \mathrm{~min}^{-1}$

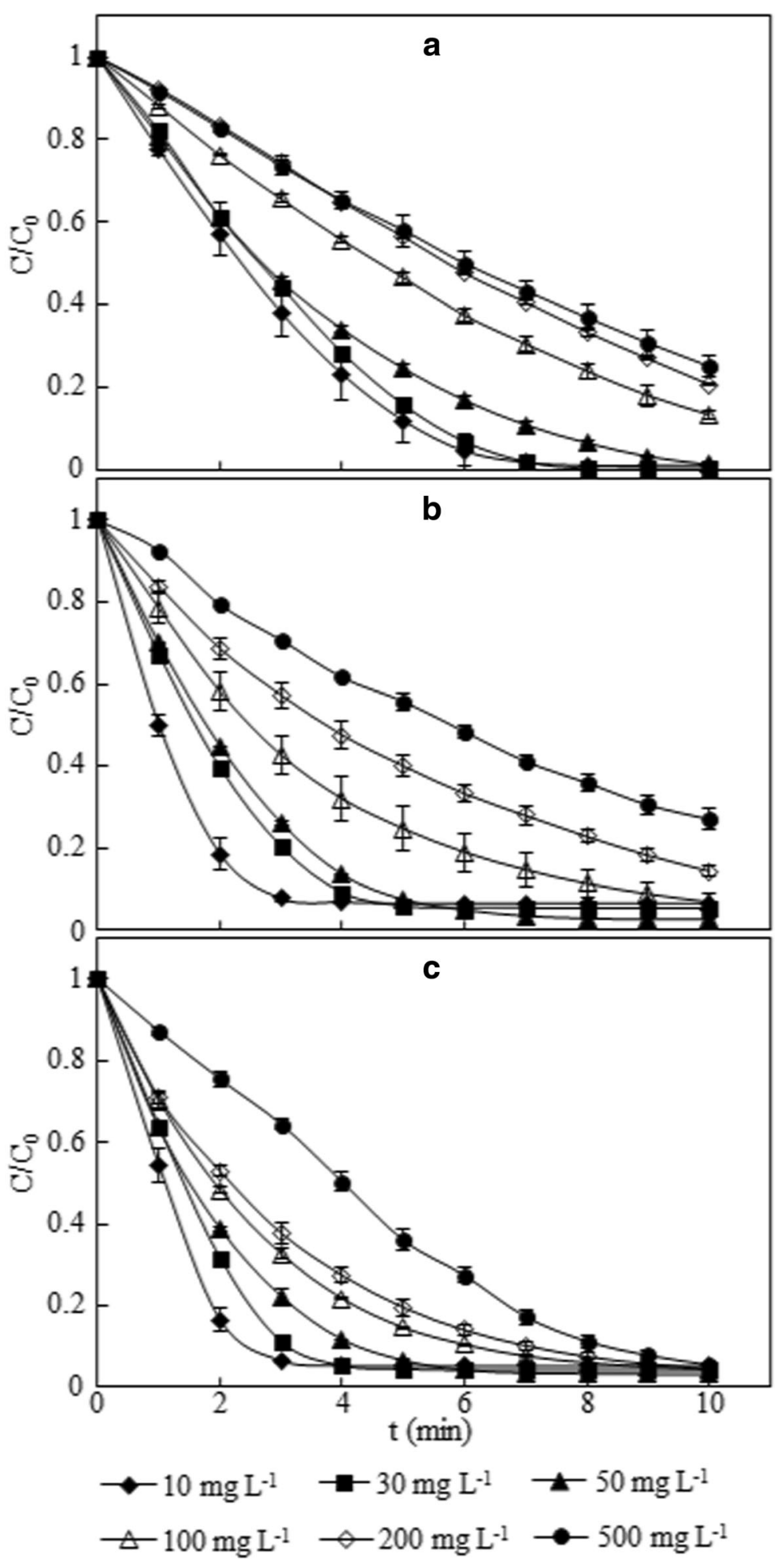


0.2 , and $0.5 \mathrm{~mol} \mathrm{~L}^{-1}$ ) was added into the aqueous solution in the catalytic ozonation system. Similarly, the effect of cations $\left(\mathrm{Ca}^{2+}\right.$ and $\left.\mathrm{Mg}^{2+}\right)$ on removal of ST, OFL, and TC was evaluated by the addition of the chloride at certain concentration $(0,0.005,0.05,0.2$, and $0.5 \mathrm{~mol} \mathrm{~L}^{-1}$ ).

\subsection{Analytical Methods}

The morphology of the nano- $\mathrm{Mg}(\mathrm{OH})_{2}$ was analyzed using Quanta-400F field emission scanning electron microscopy (SEM, PerkinElmer, America). The crystalline phase of the obtained $\mathrm{Mg}(\mathrm{OH})_{2}$ catalyst was examined by X-ray diffraction (XRD) technique (Rigaku, Japan) with $\mathrm{Cu}-\mathrm{K} \alpha$ radiation, scanning range for $2 \theta$ between $5^{\circ}$ and $80^{\circ}$. The total organic carbon (TOC) was measured by a TOC analyzer (TOC-VCPH, Shimadzu, Japan). The concentration of ST, OFL, and TC was analyzed using a EX1600 HPLC with a UV detector (Wufeng Co., Shanghai, China) and a reversephase column (Waters SunFire C18, 2.1 $\times 150 \mathrm{~mm}$, $3.5 \mu \mathrm{m})$. The mobile phase was $15 \%$ acetonitrile and $85 \%$ sodium hydrogen phosphate solution $\left(0.02 \mathrm{~mol} \mathrm{~L}^{-1}, \mathrm{pH}=2.5\right)$, and the wavelength for detecting ST, OFL, and TC was 270, 293, and $360 \mathrm{~nm}$, respectively. The gas ozone concentration was measured by iodometric method (Flamm 1977). To obtain further information on the removal behaviors of ST, OFL, and $\mathrm{TC}$ in the presence of nano- $\mathrm{Mg}(\mathrm{OH})_{2}$ catalyst, the removal kinetics was investigated. Pseudo-first-order kinetic (Eq. (1)) was used to fit the experimental data:

$\ln C_{t}=\ln C_{0}-k t$

where $C_{0}$ and $C_{t}$ are concentrations of target antibiotics at 0 and $t \mathrm{~min}$, respectively; $k\left(\mathrm{~min}^{-1}\right)$ is the degradation rate constant.

\section{Results and Discussion}

\subsection{Characterization of the Nano- $\mathrm{Mg}(\mathrm{OH})_{2}$ Catalyst} Synthesized from Natural Bischofite

The SEM image (Fig. 1) showed the synthesized nano$\mathrm{Mg}(\mathrm{OH})_{2}$ catalyst consisting of nano-flowers and the nano-flowers formed due to an assembly of nano-plates with the size in the range of $50-300 \mathrm{~nm}$. As illustrated in Fig. 2, all the diffraction peaks corresponded to the
Fig. 7 Effect of anions on the degradation of antibiotics. Effect of $\mathbf{a ~} \mathrm{Cl}^{-}, \mathbf{b ~} \mathrm{HCO}_{3}{ }^{-}$, and $\mathbf{c ~} \mathrm{SO}_{4}{ }^{2-}$ on the degradation of sulfathiazole, respectively. Effect of $\mathbf{d ~} \mathrm{Cl}^{-}$, e $\mathrm{HCO}_{3}{ }^{-}$, and $\mathbf{f} \mathrm{SO}_{4}{ }^{2-}$ on the degradation of ofloxacin. Effect of $\mathbf{g ~ C l}^{-}, \mathbf{h ~} \mathrm{HCO}_{3}{ }^{-}$, and $\mathbf{i ~} \mathrm{SO}_{4}{ }^{2-}$ on the degradation of tetracycline. Reaction conditions: antibiotics concentration $50 \mathrm{mg} \mathrm{L}^{-1}$, catalyst dosage $0.15 \mathrm{~g} \mathrm{~L}^{-1}$, ozone concentration $0.5 \mathrm{~g} \mathrm{~h}^{-1}$, ozone flow rate $0.1 \mathrm{~L} \mathrm{~min}^{-1}$

hexagonal structure of magnesium hydroxide very well according to JCPDS 7-239. The sharp peaks indicated that the prepared nano- $\mathrm{Mg}(\mathrm{OH})_{2}$ had good crystallinity. No characteristic peaks of other impurities could be detected, indicating that high-purity nano- $\mathrm{Mg}(\mathrm{OH})_{2}$ was successfully prepared.

\subsection{Removal of Antibiotics in the Presence of Synthesized Nano- $\mathrm{Mg}(\mathrm{OH})_{2}$}

The catalytic ozonation performance of the nano$\mathrm{Mg}(\mathrm{OH})_{2}$ was evaluated (Fig. 3). In the single ozonation process, the removal efficiency of ST, OFL, and TC could only reach $67.9 \%, 71.5 \%$, and $81.4 \%$ within $5 \mathrm{~min}$. The addition of nano- $\mathrm{Mg}(\mathrm{OH})_{2}$ into the ozonation system caused a significant improvement for the removal of ST, OFL, and TC. The removal efficiency of ST, OFL, and TC in the catalytic ozonation process reached $75.5 \%, 92.6 \%$, and $93.4 \%$ within 5 min while complete removal of ST, OFL, and TC was observed within $10 \mathrm{~min}$. The adsorptive removal could be neglected since the ST, OFL, and TC adsorption onto nano- $\mathrm{Mg}(\mathrm{OH})_{2}$ was just around $1 \%$ after $10 \mathrm{~min}$, suggesting that the removal of ST, OFL, and TC was mainly caused by oxidation. Based on the results obtained in the TOC variation (Fig. 3b, $\mathrm{d}, \mathrm{f}$ ), the TOC of ST, OFL, and TC adsorption onto nano- $\mathrm{Mg}(\mathrm{OH})_{2}$ was around $2.3 \%, 1.9 \%$, and $1.2 \%$ after $60 \mathrm{~min}$. The mineralization of ST, OFL, and TC in the single ozonation process was $14.9 \%$, $18.7 \%$, and $17.8 \%$, respectively, at the reaction time of $60 \mathrm{~min}$. However, with the presence of nano$\mathrm{Mg}(\mathrm{OH})_{2}$ catalyst, an improvement of the ST, OFL, and TC mineralization was achieved. The mineralization of ST, OFL, and TC in the catalytic ozonation process reached $37.6 \%, 47.3 \%$, and $37.7 \%$ within $60 \mathrm{~min}$. The experimental results clearly showed that catalyst $\mathrm{Mg}(\mathrm{OH})_{2}$ had a synergistic effect on the removal of abovementioned antibiotics. The high removal efficiency of target antibiotics indicated that the nano- $\mathrm{Mg}(\mathrm{OH})_{2}$ is a promising ozonation catalyst for the removal of antibiotics. Although investigations 


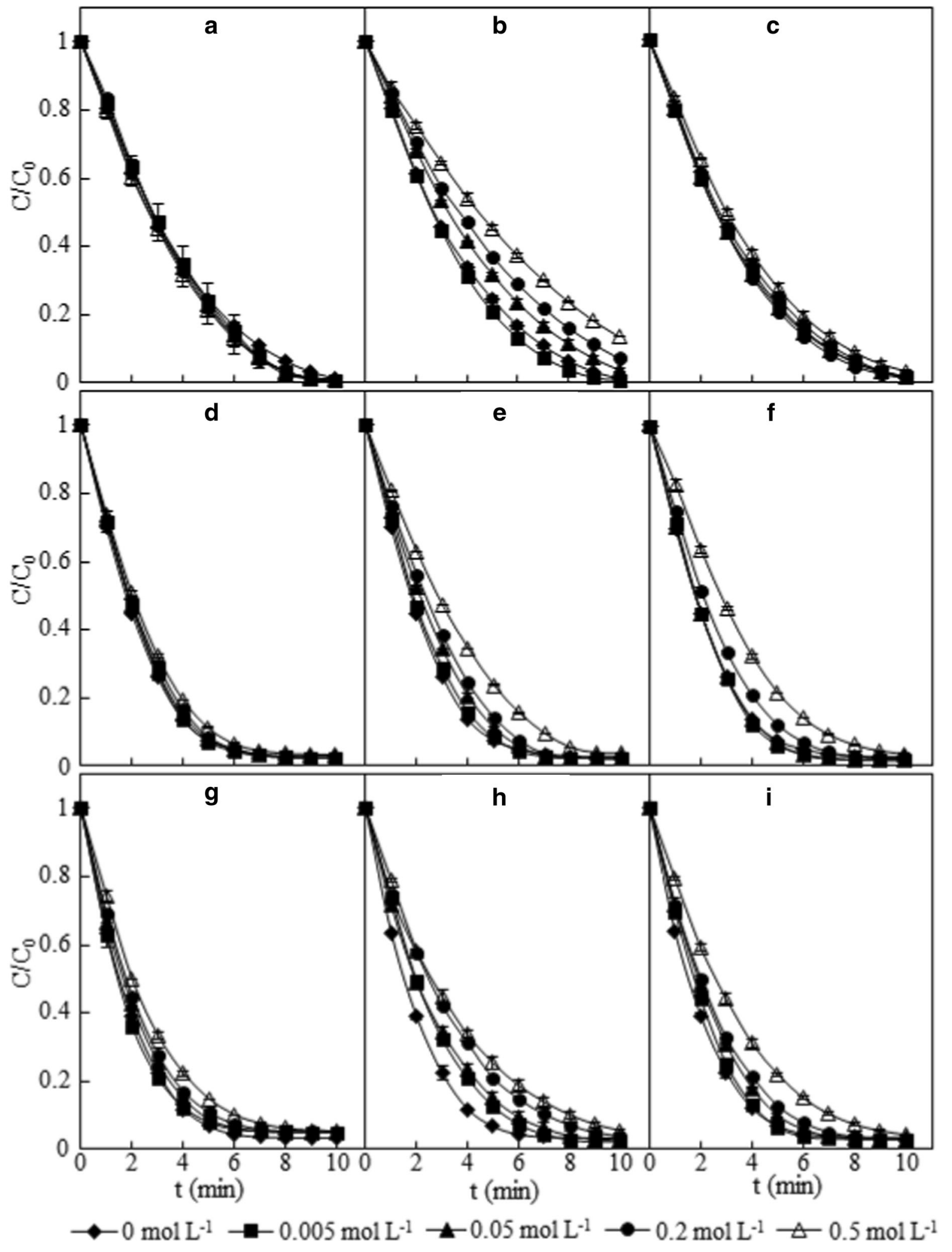


have been conducted on the ozonation of antibiotics by different catalytic methods or catalysis (Wang et al. 2012; Hou et al. 2013a, b), rare reports are available on the catalytic ozonation of these widely used antibiotics including ST, OFL, and TC using nano- $\mathrm{Mg}(\mathrm{OH})_{2}$ as catalyst. The results of this study provided new promising catalyst on the ozonation of antibiotics.

Based on the experimental data, the pseudo-firstorder kinetic model had a good fitness $\left(R^{2}>0.97\right)$ for the removal of ST, OFL, and TC. The removal rate constant of ST increased by $23.5 \%$ from 0.298 to $0.368 \mathrm{~min}^{-1}$ with added catalyst. The removal rate constant of OFL in the catalytic ozonation treatment $\left(\mathrm{k}_{\mathrm{OFL}}=0.512 \mathrm{~min}^{-1}\right)$ was nearly 2.1 times higher than the single ozonation $\left(\mathrm{k}_{\mathrm{OFL}}=0.249 \mathrm{~min}^{-1}\right)$. The removal rate constant of TC increased from 0.384 to $0.510 \mathrm{~min}^{-1}$ when the catalyst was added to the reaction system. This results confirmed the considerable catalytic performance of synthesized $\mathrm{Mg}(\mathrm{OH})_{2}$ on the ozonation of ST, OFL and TC.

\subsection{Effect of Radical Scavengers on the Removal of Antibiotics}

Organic pollutants could be removed via direct oxidation by ozone or indirect radical oxidation by hydroxyl radical in the ozonation system (Snyder et al. 2006; Wang and Xu 2012). In order to know which oxidation type played a major role in removing the antibiotics, TBA was selected as radical scavenger possessing the reaction rate constant of $6.0 \times 10^{8} \mathrm{M}^{-1} \mathrm{~s}^{-1}$ with hydroxyl radical (Buxton 1988) and $3.0 \times 10^{-3} \mathrm{M}^{-1} \mathrm{~s}^{-1}$ with ozone (Hoigné and Bader 1983). The presence of TBA accelerated the removal of ST, OFL, and TC in both single and catalytic ozonation (Fig. 4). After 5 min, removal rate of ST, OFL, and TC reached $75.5 \%, 92.6 \%$, and $93.4 \%$ in the absence of scavenger in catalytic ozonation. However, the removal rate of ST, OFL, and TC increased to $92.4 \%$, $97.3 \%$, and $95.3 \%$ when TBA was added, indicating that mechanisms other than radical-type oxidation might have been involved in the process of ozonation (Moussavi et al. 2010). According to a previous investigation on the catalytic ozonation of phenol in the presence of $\mathrm{MgO}$ (Moussavi et al. 2010), the similar mechanisms were proposed for
Fig. 8 Effect of cations on the degradation of antibiotics. Effect of $\mathrm{Ca}^{2+}$ on the degradation of a sulfathiazole, $\mathbf{c}$ ofloxacin, and $\mathbf{e}$ tetracycline. Effect of $\mathrm{Mg}^{2+}$ on the degradation of $\mathbf{b}$ sulfathiazole, $\mathbf{d}$ ofloxacin, and $\mathbf{f}$ tetracycline. Reaction conditions: antibiotics concentration $50 \mathrm{mg} \mathrm{L}^{-1}$, catalyst dosage $0.15 \mathrm{~g} \mathrm{~L}^{-1}$, ozone concentration $0.5 \mathrm{~g} \mathrm{~h}^{-1}$, ozone flow rate $0.1 \mathrm{~L} \mathrm{~min}^{-1}$

the ozonation of the antibiotics (ST, OFL, and TC) in the presence of nano- $\mathrm{Mg}(\mathrm{OH})_{2}$.

On the catalyst surface:

Radical type catalytic oxidation

$\mathrm{Mg}(\mathrm{OH})_{2}-\mathrm{S}+\mathrm{O}_{3} \rightarrow \mathrm{Mg}(\mathrm{OH})_{2}-\mathrm{S}^{\mathrm{O}=\mathrm{O}-\mathrm{O}}$

$\mathrm{Mg}(\mathrm{OH})_{2}-\mathrm{s}^{\mathrm{O}=\mathrm{O}-\mathrm{O}} \rightarrow \mathrm{Mg}(\mathrm{OH})_{2}-\mathrm{s}^{\mathrm{O} \cdot}+\mathrm{O}_{2}$

$\mathrm{Mg}(\mathrm{OH})_{2}-\mathrm{s}^{\mathrm{O} \cdot}+$ antibiotics $\rightarrow \mathrm{CO}_{2}+\mathrm{H}_{2} \mathrm{O}$

+ intermediates

Direct oxidation with ozone molecules

$\mathrm{Mg}(\mathrm{OH})_{2}{ }^{-\mathrm{O}_{3}}+$ antibiotics $\rightarrow \mathrm{CO}_{2}+\mathrm{H}_{2} \mathrm{O}$

+ intermediates

In the bulk solution:

Direct oxidation with ozone molecules

$\mathrm{O}_{3}+$ antibiotics $\rightarrow \mathrm{CO}_{2}+\mathrm{H}_{2} \mathrm{O}+$ intermediates

On the surface of nano- $\mathrm{Mg}(\mathrm{OH})_{2}$, hydrogen bounds are formed through the combination ozone molecules with hydroxyl groups (Eq. (2)). Then, the part of bounded ozone to decompose into atomic oxygen (Eq. (3)), which accelerate the catalytic ozonation of the antibiotics (Eq. (4)). Undissociated ozone bounded with the nano- $\mathrm{Mg}(\mathrm{OH})_{2}$ can also directly oxidized the antibiotics having contact with it (Eq. (5)). Additionally, ozone and antibiotics solubilized in the solution could directly react with each other in the bulk solution, resulting into part degradation of the antibiotics (Eq. (6)).

\subsection{Effect of Temperature on the Removal of Antibiotics}

Influence of temperature on the removal of ST, OFL, and TC is shown in Fig. 5. The removal rate constant of ST greatly increased from 0.259 to $0.604 \mathrm{~min}^{-1}$ when the reaction temperature increased from 15 to $35^{\circ} \mathrm{C}$, 

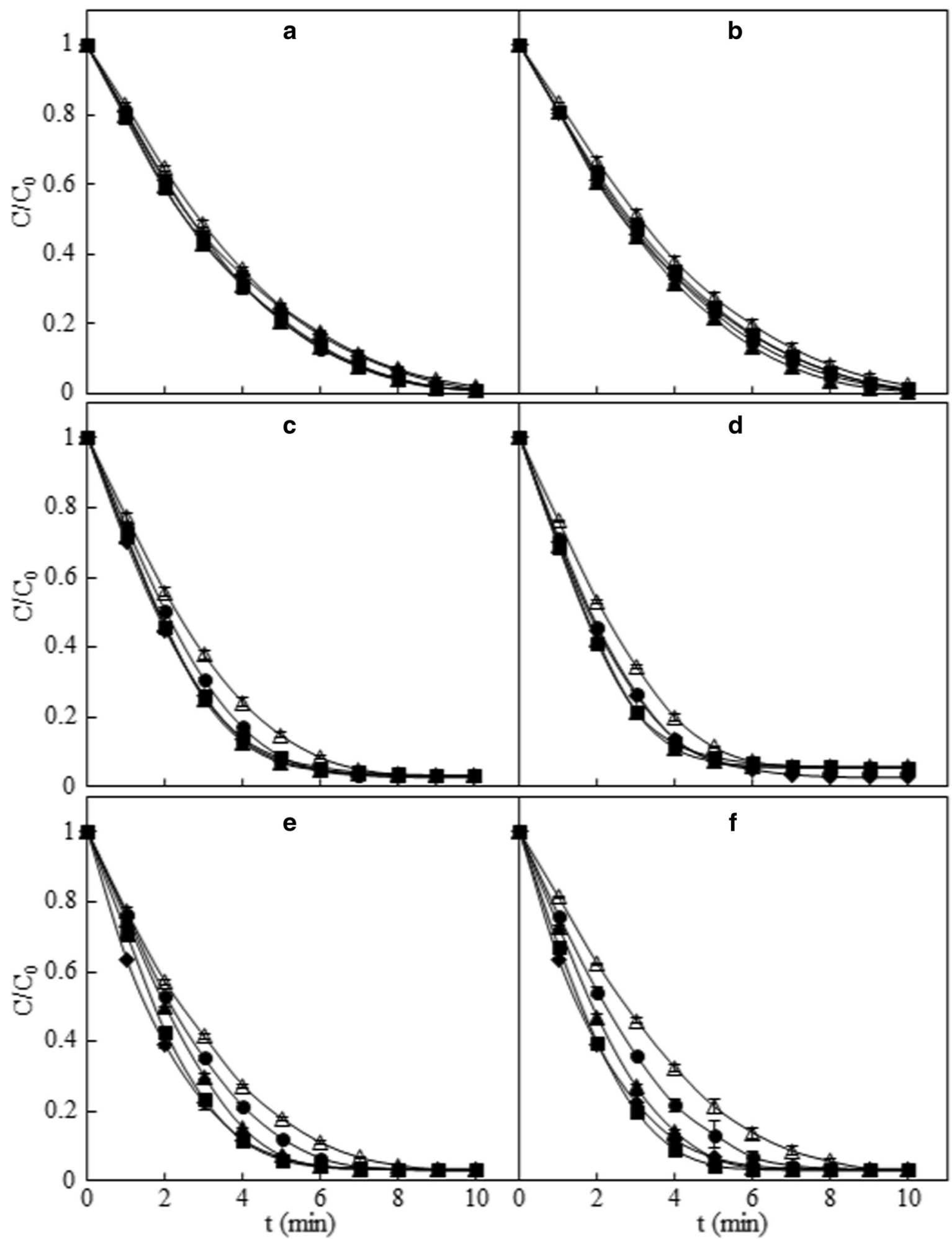

$\rightarrow 0 \mathrm{~mol} \mathrm{~L}-1 \rightarrow-0.005 \mathrm{~mol} \mathrm{~L}^{-1} \rightarrow 0.05 \mathrm{~mol} \mathrm{~L}^{-1} \rightarrow 0.2 \mathrm{~mol} \mathrm{~L}^{-1} \triangle 0.5 \mathrm{~mol} \mathrm{~L}^{-1}$ 
which was similar with other investigations on the ozonation of phenol and nitrobenzene using magnesia as catalyst (Dong et al. 2007; He et al. 2008). The increase in temperature usually accelerate reaction rate and mass transfer (Kwan and Chu 2004), which directly improves the removal efficiency of antibiotics and yields higher chemical reaction rate constant. However, the variation of reaction temperature almost did not affect the removal rate of OFL and TC. The removal rate constants of OFL/TC slightly increased from 0.489 / 0.497 to $0.512 / 0.510 \mathrm{~min}^{-1}$, respectively, when the temperature increased from 15 to $25^{\circ} \mathrm{C}$. The removal efficiencies of OFL and TC were slightly suppressed when the temperature further increased to $35^{\circ} \mathrm{C}$. The removal rate constants of OFL and TC slightly decreased by $2.15 \%$ and $0.78 \%$, respectively, when the temperature increased from 25 to $35^{\circ} \mathrm{C}$. The above abnormal phenomena are caused by the balance of both the solubility of ozone and reaction rate of ozonization. On the other side, the solubility of ozone decreases in aqueous phase as the temperature rises (Giri et al. 2008). The joint result of the two opposite effects led to the above observations regarding the influence of temperature on the catalytic ozonation of OFL and TC. Similar phenomenon was observed in a previous investigation on using natural brucite to enhance the ozonation of phenol (He et al. 2008).

3.5 Effect of Initial Concentration of Target Antibiotics on the Removal of Antibiotics

The increase in the initial concentration of the antibiotics led to the decrease in the removal efficiency (Fig. 6). The removal rate of ST reached $95.5 \%$ after 6 min with the initial concentration of $10 \mathrm{mg} \mathrm{L}^{-1}$ while that for the initial concentration of 30, 50, 100, 200, and $500 \mathrm{mg} \mathrm{L}^{-1}$ were only $93.2 \%, 83.2 \%, 62.6 \%, 52.4 \%$, and $50.1 \%$, respectively. Meanwhile, the removal rate constant decreased $77.5 \%$ from 0.582 to $0.131 \mathrm{~min}^{-1}$ when the initial concentration of ST increased from 10 to $500 \mathrm{mg} \mathrm{L}^{-1}$. A similar sharp decline was also observed in the removal of OFL and TC. The concentration of degradation intermediates might increase with the increase of initial concentration of the antibiotics, which led to the additional ozone consumption for the further removal and oxidation of intermediates ( $\mathrm{Li}$ et al. 2009; Lü et al. 2015). Additionally, the excessive antibiotics and organic intermediates could also be adsorbed on the
Fig. 9 The stability and durability of nano- $\mathrm{Mg}(\mathrm{OH})_{2}$ in the catalytic ozonation of sulfathiazole (circles), ofloxacin (triangles), and tetracycline (diamonds). Reaction conditions: antibiotics concentration $50 \mathrm{mg} \mathrm{L}^{-1}$, catalyst dosage $0.15 \mathrm{~g} \mathrm{~L}^{-1}$, ozone concentration $0.5 \mathrm{~g} \mathrm{~h}^{-1}$, ozone flow rate $0.1 \mathrm{~L} \mathrm{~min}^{-1}$

catalyst surface, suppressing the surface reactions and resulting in reduced removal efficiency (Bai et al. 2016).

\subsection{Effect of Anions on the Removal of Antibiotics}

The effect of anions $\left(\mathrm{Cl}^{-}, \mathrm{HCO}_{3}{ }^{-}\right.$, and $\left.\mathrm{SO}_{4}{ }^{2-}\right)$ on the removal of ST, OFL, and TC in catalytic ozonation was evaluated (Fig. 7). The $\mathrm{Cl}^{-}$addition illustrated negligible effect on removal of antibiotics. The removal rate constant of ST, OFL, and TC decreased by $1.22 \%$, $12.3 \%$, and $32.3 \%$, respectively, when the initial concentration of $\mathrm{Cl}^{-}$increased from 0 to $0.5 \mathrm{~mol} \mathrm{~L}^{-1}$. The removal of ST, OFL, and TC was obviously inhibited when the concentration of $\mathrm{HCO}_{3}{ }^{-}$increased from 0 to $0.5 \mathrm{~mol} \mathrm{~L}^{-1}$. The removal rate constants of ST, OFL, and TC decreased by $49.1 \%, 28.8 \%$, and $42.7 \%$, respectively. In the case of $\mathrm{SO}_{4}{ }^{2-}$, similar harmful effect on the removal of ST, OFL, and TC was also observed. The removal rate constant of TC decreased by $34.1 \%$ when the concentration of $\mathrm{SO}_{4}{ }^{2-}$ increased from 0 to $0.5 \mathrm{~mol} \mathrm{~L}^{-1}$. The increase in the concentration of $\mathrm{SO}_{4}{ }^{2}$ also led to the decrease in the removal efficiency of ST and OFL. These results suggested that the addition of anions $\left(\mathrm{Cl}^{-}, \mathrm{HCO}_{3}{ }^{-}\right.$, and $\left.\mathrm{SO}_{4}{ }^{2-}\right)$ inhibited the removal of ST, OFL, and TC. The adsorption of the anions on the catalyst could lead to catalyst contamination and reduction in numbers of reaction sites on catalyst surface, which subsequently hindered the degradation of antibiotics (Yuan et al. 2013).

\subsection{Effect of Cations on the Removal of Antibiotics}

The depressing effect of $\mathrm{Ca}^{2+}$ and $\mathrm{Mg}^{2+}$ on the catalytic ozonation of ST, OFL, and TC was observed at relatively high concentration (Fig. 8). At relatively low concentration $\left(<0.05 \mathrm{~mol} \mathrm{~L}^{-1}\right), \mathrm{Ca}^{2+}$ and $\mathrm{Mg}^{2+}$ slightly promoted the removal of ST. Both of $\mathrm{Ca}^{2+}$ and $\mathrm{Mg}^{2+}$ hindered the removal of ST in catalytic ozonation process when their concentration increased from 0.05 to $0.5 \mathrm{~mol} \mathrm{~L}^{-1}$. When the concentration of $\mathrm{Ca}^{2+}$ increased from 0 to $0.5 \mathrm{~mol} \mathrm{~L}^{-1}$, the removal rate constant of OFL and TC decreased by $21.8 \%$ and $26.2 \%$, respectively. The removal rate constant of OFL and TC decreased by 

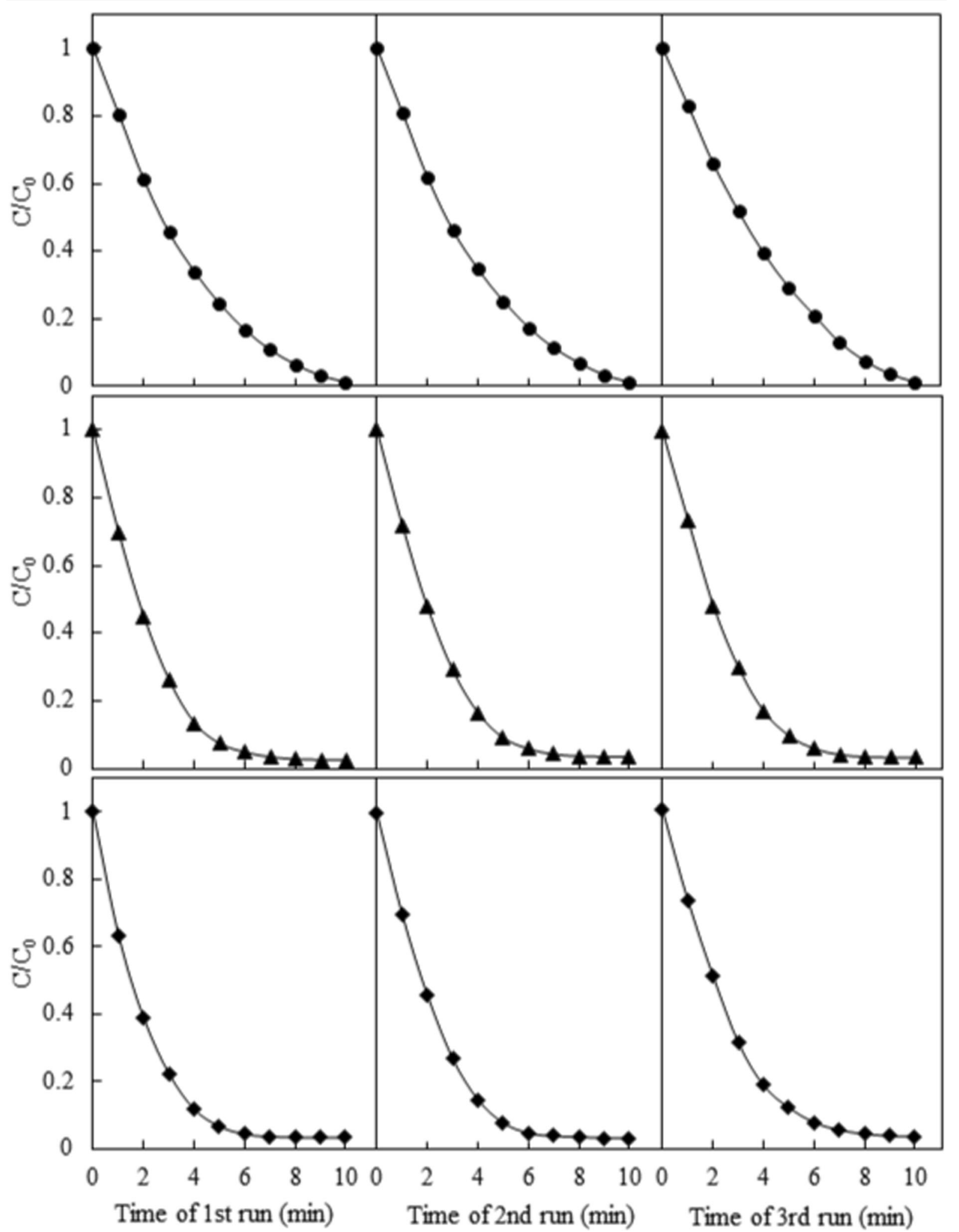
$20.9 \%$ and $31.7 \%$, respectively, when the concentration of $\mathrm{Mg}^{2+}$ increased from 0 to $0.5 \mathrm{~mol} \mathrm{~L}^{-1}$. The $\mathrm{Ca}^{2+}$ and $\mathrm{Mg}^{2+}$ are stable and do not participate in the reaction (Song et al. 2016). The adsorption of these cations on the catalyst might also lead to catalyst contamination and reduction in numbers of reaction sites on catalyst surface, which subsequently jeopardized the degradation of antibiotics.

\subsection{The Reusability of the Catalyst}

The stability of the catalyst in their reuse was worth studying from a practical standpoint. Thus, three successive tests for catalytic ozonation of ST, OFL, and TC were conducted. At the end of each test, the catalyst was separated by centrifugation and the separated catalyst was dried at $60{ }^{\circ} \mathrm{C}$ and reused for the next test without further modification. In Fig. 9, the removal efficiency of ST, OFL, and TC was not significantly affected and their removal efficiency remained above $90 \%$ after the nano$\mathrm{Mg}(\mathrm{OH})_{2}$ was repeatedly used for three times. These results indicated that the prepared nano- $\mathrm{Mg}(\mathrm{OH})_{2}$ catalyst was a reusable catalyst which can maintain its catalytic activity.

\section{Conclusion}

The nano- $\mathrm{Mg}(\mathrm{OH})_{2}$ synthesized from natural bischofite showed high catalytic activity and mineralization for the ozonation of antibiotics including ST, OFL, and TC. The removal of ST, OFL, and TC followed pseudofirst-order kinetic model. Mechanisms other than radical-type oxidation might have been involved in the process of antibiotic removal according to experimental results of adding radical scavenger. The ST removal rate strongly increased with the increase of temperature, but the variation of reaction temperature almost did not affect the removal of OFL and TC. Increase in the initial concentration of antibiotics led to the decrease in the removal efficiency of ST, OFL, and TC. All anions and cations were disadvantageous to the removal of ST, OFL, and TC at the higher concentration. The nano$\mathrm{Mg}(\mathrm{OH})_{2}$ catalyst could maintain its stable catalytic activity during the continuous use process. In conclusion, high removal efficiency of typical antibiotics and heavy metals free suggested that nano- $\mathrm{Mg}(\mathrm{OH})_{2}$ from natural bischofite is a promising ozonation catalyst in the terms of antibiotics removal.
Funding This work was financially supported by the National Natural Science Foundation of China (No. 41671319), One Hundred Talents Program of Chinese Academy of Sciences (grant numbers Y629041021 and Y610061033), Taishan Scholar Program of Shandong Province, Thousand Talents Plan of Qinghai Province (Y740171071), and Two-Hundred Talents Plan of Yantai (No. Y739011021).

Publisher's Note Springer Nature remains neutral with regard to jurisdictional claims in published maps and institutional affiliations.

\section{References}

Amutha, R., Sillanpää, M., Lee, G. J., Lin, J. C., Yang, C. K., \& Wu, J. J. (2014). Catalytic ozonation of 2-ethoxy ethyl acetate using mesoporous nickel oxalates. Catalysis Communications, 43, 88-92.

Bai, Z., Yang, Q., \& Wang, J. (2016). Catalytic ozonation of sulfamethazine using $\mathrm{Ce}_{0.1} \mathrm{Fe}_{0.9} \mathrm{OOH}$ as catalyst: Mineralization and catalytic mechanisms. Chemical Engineering Journal, 300, 169-176.

Brown, K. D., Kulis, J., Thomson, B., Chapman, T. H., \& Mawhinney, D. B. (2006). Occurrence of antibiotics in hospital, residential, and dairy effluent, municipal wastewater, and the Rio Grande in New Mexico. Science of the Total Environment, 366, 772-783.

Buxton, G. V. (1988). Critical view of rate constants for reactions of hydrated electrons, hydrogen atoms and hydroxyl radicals $\left(\cdot \mathrm{OH} / \cdot \mathrm{O}^{-}\right)$in aqueous solution. Journal of Physical \& Chemical Reference Data, 17, 513-886.

Carvalho, I. T., \& Santos, L. (2016). Antibiotics in the aquatic environments: A review of the European scenario. Environment International, 94, 736-757.

Changotra, R., Guin, J. P., Varshney, L., \& Dhir, A. (2018). Assessment of reaction intermediates of gamma radiationinduced degradation of ofloxacin in aqueous solution. Chemosphere, 208, 606-613.

Dong, Y., He, K., Yin, L., \& Zhang, A. (2007). Catalytic degradation of nitrobenzene and aniline in presence of ozone by magnesia from natural mineral. Catalysis Letters, 119, 222227.

Flamm, D. L. (1977). Analysis of ozone at low concentrations with boric acid buffered KI. Environmental Science \& Technology, 11, 978-983.

Giri, R. R., Ozaki, H., Taniguchi, S., \& Takanami, R. (2008). Photocatalytic ozonation of 2,4-dichlorophenoxyacetic acid in water with a new $\mathrm{TiO}_{2}$ fiber. International Journal of Environmental Science \& Technology, 5, 17-26.

Gonçalves, A. G., Órfão, J. J. M., \& Pereira, M. F. R. (2012). Catalytic ozonation of sulphamethoxazole in the presence of carbon materials: Catalytic performance and reaction pathways. Journal of Hazardous Materials, 239-240, 167-174.

He, K., Dong, Y. M., Li, Z., Yin, L., Zhang, A. M., \& Zheng, Y. C. (2008). Catalytic ozonation of phenol in water with natural brucite and magnesia. Journal of Hazardous Materials, 159, 587-592. 
Hoigné, J., \& Bader, H. (1983). Rate constants of reactions of ozone with organic and inorganic compounds in water-I nondissociating organic compounds. Water Research, 17, 173183.

Hou, L., Zhang, H., Wang, L., Chen, L., Xiong, Y., \& Xue, X. (2013a). Removal of sulfamethoxazole from aqueous solution by sono-ozonation in the presence of a magnetic catalyst. Separation \& Purification Technology, 117, 46-52.

Hou, L., Zhang, H., Wang, L., \& Chen, L. (2013b). Ultrasoundenhanced magnetite catalytic ozonation of tetracycline in water. Chemical Engineering Journal, 229, 577-584.

Kim, S. D., Cho, J., Kim, I. S., Vanderford, B. J., \& Snyder, S. A. (2007). Occurrence and removal of pharmaceuticals and endocrine disruptors in South Korean surface, drinking, and waste waters. Water Research, 41, 1013-1021.

Kümmerer, K. (2001). Drugs in the environment: Emission of drugs, diagnostic aids and disinfectants into wastewater by hospitals in relation to other sources-a review. Chemosphere, 45, 957-969.

Kümmerer, K. (2009). Antibiotics in the aquatic environment-a review-part II. Chemosphere, 75, 435-441.

Kwan, C. Y., \& Chu, W. (2004). A study of the reaction mechanisms of the degradation of 2,4-dichlorophenoxyacetic acid by oxalate-mediated photooxidation. Water Research, 38, 4213-4221.

Li, L., Ye, W., Zhang, Q., Sun, F., Ping, L., \& Li, X. (2009). Catalytic ozonation of dimethyl phthalate over cerium supported on activated carbon. Journal of Hazardous Materials, $170,411-416$

Lü, X., Zhang, Q., Yang, W., Li, X., Zeng, L., \& Li, L. (2015). Catalytic ozonation of 2,4-dichlorophenoxyacetic acid over novel Fe-Ni/AC. RSC Advances, 5, 10537-10545.

Managaki, S., Murata, A., Takada, H., Tuyen, B. C., \& Chiem, N. H. (2007). Distribution of macrolides, sulfonamides, and trimethoprim in tropical waters: Ubiquitous occurrence of veterinary antibiotics in the Mekong Delta. Environmental Science \& Technology, 41, 8004-8010.

Miao, X. S., Bishay, F., Chen, M., \& Metcalfe, C. D. (2004). Occurrence of antimicrobials in the final effluents of wastewater treatment plants in Canada. Environmental Science \& Technology, 38, 3533-3541.

Moussavi, G., Khavanin, A., \& Alizadeh, R. (2010). The integration of ozonation catalyzed with $\mathrm{MgO}$ nanocrystals and the biodegradation for the removal of phenol from saline wastewater. Applied Catalysis B Environmental, 97, 160-167.

Peng, X., Wang, Z., Kuang, W., Tan, J., \& Li, K. (2006). A preliminary study on the occurrence and behavior of sulfonamides, ofloxacin and chloramphenicol antimicrobials in wastewaters of two sewage treatment plants in Guangzhou, China. Science of the Total Environment, 371, 314-322.

Snyder, S. A., Wert, E. C., Rexing, D. J., Zegers, R. E., \& Drury, D. D. (2006). Ozone oxidation of endocrine disruptors and pharmaceuticals in surface water and wastewater. Ozone Science \& Engineering, 28, 445-460.

Song, C., Wang, L., Ren, J., Lv, B., Sun, Z., Yan, J., Li, X., \& Liu, J. (2016). Comparative study of diethyl phthalate degradation by $\mathrm{UV} / \mathrm{H}_{2} \mathrm{O}_{2}$ and $\mathrm{UV} / \mathrm{TiO}_{2}$ : Kinetics, mechanism, and effects of operational parameters. Environmental Science \& Pollution Research, 23, 2640-2650.

Tian, Y., Gao, B., Morales, V. L., Chen, H., Wang, Y., \& Li, H. (2013). Removal of sulfamethoxazole and sulfapyridine by carbon nanotubes in fixed-bed columns. Chemosphere, 90, 2597-2605.

Trovó, A. G., Nogueira, R. F., Agüera, A., Fernandezalba, A. R., Sirtori, C., \& Malato, S. (2009). Degradation of sulfamethoxazole in water by solar photo-Fenton. Chemical and toxicological evaluation. Water Research, 43, 3922-3931.

Vieno, N. M., Härkki, H., Tuhkanen, T., \& Kronberg, L. (2007). Occurrence of pharmaceuticals in river water and their elimination in a pilot-scale drinking water treatment plant. Environmental Science \& Technology, 41, 5077-5084.

Wang, J. L., \& Xu, L. J. (2012). Advanced oxidation processes for wastewater treatment: Formation of hydroxyl radical and application. Critical Reviews in Environmental Science \& Technology, 42, 251-325.

Wang, W., Qiao, X., Chen, J., \& Li, H. (2007). Facile synthesis of magnesium oxide nanoplates via chemical precipitation. Materials Letters, 61, 3218-3220.

Wang, Y., Zhang, H., Chen, L., Wang, S., \& Zhang, D. (2012). Ozonation combined with ultrasound for the degradation of tetracycline in a rectangular air-lift reactor. Separation \& Purification Technology, 84, 138-146.

Yan, C., Yang, Y., Zhou, J., Liu, M., Nie, M., Shi, H., \& Gu, L. (2013). Antibiotics in the surface water of the Yangtze Estuary: Occurrence, distribution and risk assessment. Environmental Pollution, 175, 22-29.

Yin, R., Guo, W., Du, J., Zhou, X., Zheng, H., Wu, Q., Chang, J., \& Ren, N. (2017). Heteroatoms doped graphene for catalytic ozonation of sulfamethoxazole by metal-free catalysis: Performances and mechanisms. Chemical Engineering Journal, 317, 632-639.

Yuan, R., Zhou, B., Hua, D., \& Shi, C. (2013). Enhanced photocatalytic degradation of humic acids using $\mathrm{Al}$ and $\mathrm{Fe}$ codoped $\mathrm{TiO}_{2}$ nanotubes under UV/ozonation for drinking water purification. Journal of Hazardous Materials, 262, $527-538$. 
Reproduced with permission of copyright owner. Further reproduction prohibited without permission. 